\title{
Concepção de estudantes de psicologia sobre diversidade sexual: reflexões sobre o fazer psicológico
}

\author{
Conception of Psychology students about sexual diversity: \\ reflections about the psychological practice \\ Percepción de los estudiantes de Psicología sobre diversidad sexual: \\ reflexiones acerca de la práctica psicológica \\ Aline Kogima Santana SANTOS ${ }^{1}$ \\ Flávia Cristina Santiago de OLIVEIRA ${ }^{1}$ \\ Larissa Cristina Melinsky dos SANTOS1 \\ LUCAS FERREIRA SOBRINHO'1 \\ Vivian Daniele Martins de SOUZA 1 \\ Eni de Fátima MARTINS ${ }^{2}$ \\ ${ }^{1}$ Graduação em Psicologia pela Universidade Paulista UNIP - Campus Araçatuba, 16018-555 Araçatuba-SP, Brasil \\ ${ }^{2}$ Doutora em Psicologia da Educação pela Pontifícia Universidade Católica de São Paulo; \\ Fundação Educacional de Penápolis - FUNEPE, 160300-000 Penápolis-SP, Brasil
}

\section{Resumo}

Diante de uma sociedade marcada pela heteronormatividade, a Psicologia enquanto ciência necessita refletir e desempenhar uma práxis que possa contribuir com a inclusão da População LGBTT, a fim de não reproduzir premissas que possam corroborar com ideias heteronormativas e estereotipadas na prática psicológica que possuem poder de exclusão. O presente estudo trata-se de uma pesquisa qualitativa acerca da concepção de estudantes de Psicologia sobre diversidade sexual, com ênfase nas Políticas Públicas. Foram entrevistados dez estudantes de Psicologia a partir do sétimo semestre de uma cidade do interior paulista. Os entrevistados participaram de forma livre e voluntária do estudo, pautados pelo termo de consentimento livre e esclarecido. A pesquisa consistiu em entrevistas semi-estruturadas com sete questões abertas, onde os participantes analisaram situações fictícias abrangendo os temas de Políticas Públicas e atuação do Psicólogo em diversos contextos, dentro do tema de diversidade sexual. Para analisar os dados, foi utilizada a estratégia de núcleos de significação proposto por Aguiar e Ozella (2006), fundamentando-se na perspectiva da Psicologia Histórico-Cultural como base epistemológica. Os resultados mostraram que em sua maioria, os acadêmicos salientam a importância de uma atuação reflexiva acerca dos temas que envolvem a diversidade sexual, buscando esclarecer e desmistificar pré-conceitos e promovendo a inclusão daqueles que sofrem discriminação. A partir das análises, conclui-se que há insciência por parte de alguns estudantes acerca de temas específicos da Diversidade Sexual, entretanto, a pesquisa apresenta direções para novos estudos ligados ao tema, sendo este relevante ao âmbito acadêmico, e fundamentalmente relevante à sociedade.

Descritores: Sexualidade; Atuação (Psicologia); Políticas Públicas.

\section{Abstract}

In a society characterized by heteronormativity, Psychology as science needs to reflect and make a practice that contribute to include the LGBTT population in order to avoid perpetuating stereotyped ideas that create discrimination. The proposed qualitative research aims to identify the preconceptions of Psychology students in regards to sexual diversity, with emphasis on public policy implications. The researchers interviewed ten Psychology students from São Paulo's countryside, all of them above the seventh semester. The participants joined voluntarily and gave full consent. The interviews were semi structured and presented the students with seven open-ended questions to analyzed fictitious situations about Public Policies issues and the Psychological Practice in different contexts and areas, all inside the main theme, which is sexual diversity. The "Meaning Core Strategy", proposed by Aguiar and Ozella (2006), was used to analyze the data, based on the Cultural-Historical Psychology as an epistemological base. The results shows that the most part of the academics emphasized the importance of reflexive actuation and hope to clarify and demystify preconceptions about sexual orientations and ultimately promote tolerance towards those that suffer from discrimination. The analysis shows there is not much insight from the students about sexual diversity specific themes; however, the research opened new avenues for future studies related to sexual tolerance, and ultimately, society at large. Descriptors: Sexuality; Acting Out; Public Policies.

\section{Resumen}

Frente a una sociedad marcada por la heteronormatividad, la Psicología como ciencia necesita reflejar y llevar a cabo una práctica que puede contribuir a la inclusión de la población LGBTT, con el fin de no reproducir supuestos que puedan confirmar las ideas estereotipadas y heteronormativas en la práctica psicológica que tienen poder excluyente. Este estudio trata de una investigación cualitativa sobre el diseño de los estudiantes de Psicología sobre diversidad sexual, con énfasis en Política Pública. Se entrevistó a diez estudiantes de Psicología del séptimo semestre de una ciudad del Estado Sao Paulo. Los encuestados participaron libre y voluntariamente en el estudio, dirigido por el consentimiento informado. La investigación consistió en entrevistas semiestructuradas con siete preguntas abiertas, donde los participantes analizaron situaciones ficticias que cubren los temas de las políticas y acciones de los psicólogos en diferentes contextos dentro del tema diversidad sexual. Para analizar los datos, se utilizó la estrategia de núcleo de la significación propuesto por Aguiar y Ozella (2006), basándose en la perspectiva de la Psicología histórico-cultural como base epistemológica. Los resultados mostraron que en la mayoría de los casos, los investigadores hicieron hincapié en la importancia de una acción reflexiva sobre los retos de la diversidad sexual, el intento de clarificar y desmitificar los prejuicios y promover la inclusión de las personas que sufren discriminación. A partir del análisis, se concluye que hay ineptidud por algunos estudiantes sobre temas específicos de la diversidad sexual, sin embargo, la investigación presenta instrucciones para futuros estudios relacionados con el tema, que es relevante para el ámbito académico, y fundamentalmente relevante para la sociedad.

Descriptores: Sexualidad; Actuación (Psicología); Políticas Públicas.

\section{INTRODUÇÃO}

o Preconceito e discriminação em relação à diversidade sexual

Em nossa sociedade é frequente o preconceito e a discriminação em relação à diversidade sexual, inclusive em núcleos que deveriam apoiar e educar, visto que muitas pessoas, por exemplo, quando revelam sua orientação sexual ao núcleo familiar sofrem discriminação e até mesmo represálias, agressões e ameaças destes. As escolas também podem ser citadas como exemplos, tendo em vista que o uso de palavrões que, se referem a sexualidade de forma 
pejorativa, visando ofender o oprimido ou sua família, são bastante utilizados nesse espaço e tem gerado transtornos a muitos alunos. É necessário, do ponto de vista dos autores do presente artigo que, o psicólogo atue contribuindo para a superação do preconceito. Como sugere $\mathrm{Cruz}^{1}$, confirmado por Perucchi et al. ${ }^{2}$, "não há mais espaço para a ignorância sexual, homofobia e não reconhecimento da diversidade sexual e cultural".

Estudos se referem quanto à atuação e papel de determinados órgãos e profissionais frente à homofobia. Por exemplo, Nascimento, Pimentel ${ }^{3}$ relatam sobre o papel da Delegacia e Defensoria Pública no combate e prevenção da homofobia, garantindo o direito à assistência psicossocial e jurídica.

(...) desnaturalizar os ideais acerca da sexualidade de forma ampla; perceber que o padrão heteronormativo foi construído e é reconstruído sóciohistoricamente todos os dias; romper com o silêncio nas diversas situações homofóbicas; posicionar-se contra a discriminação, seja por cor, etnia, valor religioso ou outros; e, além disso, impor-se como ser político no mundo ${ }^{3}$.

Ao que se refere às problematizações necessárias à Psicologia, Santos ${ }^{4}$ aborda as produções discursivas sobre a homossexualidade e a construção da homofobia, destacando que é fundamental que a Psicologia se compreenda como prática política, pois, "a dicotomia entre clínica (no sentido mais amplo do termo) ou qualquer intervenção por parte da Psicologia e da política precisa ser problematizada a fim de que não reiteremos e perpetuemos enunciados que reforcem lógicas heteronormativas e que possuem poder de exclusão" .

- Heteronormatividade e homofobia: uma problemática social

Para compreendermos a homofobia, é importante que haja um entendimento sobre sexualidade, levando-se em conta uma construção histórica. Nesse sentido, dois pontos são importantes: a heteronormatividade e a ideologia machista.

Santos ${ }^{4}$ defende que "um olhar sobre a construção discursiva da homossexualidade nos permite problematizar como, ao longo da história, a homofobia é enunciada a partir de uma norma heterossexual". Com base em dados históricos acerca da relação de poder e sexo analisado através da concepção foucaultiana, compreendemos que o século XVII foi uma época de invenções tecnológicas de controle e do surgimento do capitalismo na qual o sexo era entendido como incompatível ao mundo do trabalho e houve o controle de discursos sobre o assunto. Inicialmente o falar do sexo foi reprimido e, posteriormente, foi regulado pela moralidade cristã e depois pela racionalidade científica.

No Brasil, silenciosamente os assuntos relativos à homossexualidade foram sendo evidenciados, visto que aprendemos a moralizar e a esconder, principalmente quando pensamos na forte influência que o cristianismo exerce em relação a este tema, já que este prega a homossexualidade como um pecado, contrário à moral cristã. Borges et al. ${ }^{5}$ afirmam que no Brasil morrem, por ano, aproximadamente 120 homossexuais, o que indica forte desrespeito à livre expressão da sexualidade e o grau de homofobia em nosso país.

Ao longo dos anos, discursos homofóbicos comumente velados ocorrem na sociedade brasileira, direcionando o pensamento dos brasileiros, em geral, para uma visão heteronormativa da sexualidade humana. A heteronormatividade é a ideia de que apenas a heterossexualidade é natural em nossa sociedade, reforçando a homofobia, e fazendo com que não se discuta e compreenda sobre gênero e diversidade sexual.

A homofobia ocorre, muitas vezes, sem questionamentos dos sujeitos envolvidos neste processo, por conta dos estados de "negação, hierarquização, diversionismo, apelo ao senso de oportunidade e antecipação fatalista" 6 nos quais estão contextualizados. A partir do entendimento destes discursos velados, a Psicologia pode contribuir para que haja uma desconstrução dos mesmos, visto que, estes discursos são nocivos a uma compreensão ampla acerca da homossexualidade, livre de estereótipos e conceitos sexistas e excludentes.

Outro aspecto a ser considerado na constituição do fenômeno da homofobia é o machismo. Para Borges et al. ${ }^{5} \mathrm{o}$ machismo, é uma das facetas que dá sustentação ao preconceito contra homossexuais. Ele é algo que vivemos e revivemos, quase todos os dias, em nosso cotidiano. Existe um sistema ideológico que dá sustentação ao machismo de forma a tornar os sexos diferentes, e mais do que isso, um dos sexos sendo dominante.

No Brasil, a sexualidade ao longo do tempo, foi colocada sob um controle sutil, saindo um pouco da visão cristã, e passando para a visão médico-científica, pautadas no Higienismo e o Eugenismo. Devido às questões da época no país, os médicos higienistas tratavam além do corpo, as emoções e a sexualidade. A homossexualidade era tida como uma doença. Tal concepção só começou a ser revista na década de 90, com a retirada da homossexualidade do Código Internacional de Doenças como um marco dessa mudança.

○ Diversidade, Psicologia e as Politicas Públicas para minorias

A implementação de Políticas Públicas voltadas ao combate à homofobia e à promoção dos direitos LGBTT's são incipientes, pouco consistentes ou mesmo inexistentes na atualidade no Brasil, não contemplando todos os direitos vinculados à sexualidade. Há ausência de uma legislação federal que explicitamente assegure direitos civis para a População LGBTT's, e frente a isso, o movimento social tem encontrado alternativas, ainda que parciais e de alcance limitado, recorrendo ao apoio de gestores públicos sensíveis às suas demandas. "O que se observa é que nunca se teve tanto e o que há é praticamente nada"7.

A Política Pública e a Psicologia como prática proeminentemente política necessitam romper com discursos e práticas homofóbicas e assim "qualquer intervenção por parte da psicologia e da política precisa ser problematizada a fim de que não reiteremos e perpetuemos enunciados que reforcem lógicas heteronormativas e que possuem poder de exclusão"4

É importante que os Psicólogos estejam atentos quanto aos seus discursos e as suas posições diante de questões relativas a sexualidade humana. Nessa direção, em 1999 o Conselho Federal de Psicologia proibiu práticas em que o psicólogo se propõe a tratar ou curar a homossexualidade, pois esta não é compreendida como doença, perversão e nem distúrbio.

O papel da Psicologia tem sido defendido no sentido de que ela não seja apenas um mero saber a serviço do poder, mas que contribua para uma prática ética que não seja heteronormativa, e nem excludente. É necessário que se contribua para que se desconstrua rótulos, estereótipos, e 
preconceitos que aparecem naturalizados em nossa sociedade $^{5}$.

o Psicologia Histórico-Cultural: algumas considerações sobre a constituição do sujeito

A Psicologia Histórico-Cultural tem como base epistemológica o Marxismo (materialismo históricodialético) e parte da premissa de que o homem é um ser histórico-social, ou seja, que não nasce formado e imutável, e sim, se constrói como homem a partir das relações que estabelece com o meio e com outros, sendo um ser ativo, histórico e social. Nesse sentido, não é só determinado pela realidade que o contém, como também determina esta realidade $^{8}$. Marques e Marques ${ }^{9}$ destacam que Vygotsky afirma que construir conhecimento decorre de uma ação partilhada, que implica num processo de mediação entre sujeitos por meio da interação do indivíduo histórico com o ambiente sociocultural onde habita. A heterogeneidade do grupo enriquece a informação e a comunicação, ampliando consequentemente as capacidades individuais ${ }^{9}$.

Para a perspectiva da psicologia Histórico-Cultural, os conceitos de sentido e significado são importantes para a análise dos fenômenos. A significação é construída na esfera social, e a internalização dependerá da mediação externa. $\mathrm{O}$ sentido pessoal refere-se a um sentido particular, dependendo de uma condição subjetiva, ou seja, o homem se apropria de conceitos construídos socialmente e nesse processo constitui também um sentido pessoal a essas significações ${ }^{8}$.

As transformações do significado ocorrem a partir de experiências vividas pelo sujeito, e também, das definições e referências de diferentes sistemas conceituais, mediadas pelo conhecimento já consolidado na cultura.

Com base nessas premissas os objetivos gerais do presente trabalho permeiam a compreensão dos sentidos e significados que estudantes de Psicologia têm sobre diversidade sexual na prática profissional do Psicólogo, em contextos das Políticas Públicas em enfrentamento dos processos de exclusão-inclusão das diferentes formas de manifestação da sexualidade humana.

Por outro lado, são objetivos específicos identificar os sentidos e significados de estudantes de Psicologia acerca da diversidade sexual; verificar os sentidos e significados que estudantes de Psicologia têm a respeito das Políticas Públicas direcionadas a inclusão da diversidade sexual; verificar os sentidos e significados que estudantes de Psicologia têm a respeito da determinação ou não das Políticas Públicas sobre o fazer Psicológico nos processos de exclusão-inclusão da diversidade sexual.

O levantamento da literatura realizado permitiu verificar que nossa sociedade carece de uma mudança na concepção que tem acerca da diversidade sexual, ainda observada por muitos indivíduos de forma preconceituosa e embasada em conceitos discriminatórios que são reforçados "por lógicas heteronormativas e que possuem poder de exclusão". Desse modo, identificou-se como hipótese inicial que seria possível nos deparar com preconceito velado por parte de sujeitos colaboradores com a pesquisa em relação à diversidade sexual, pautados pela reprodução de discursos de uma sociedade que ainda hoje é repleta de exclusão e discriminação.

\section{MATERIAL E MÉTODO}

A amostra dos sujeitos participantes da pesquisa foi escolhida por conveniência. Tal técnica pertence ao grupo de amostragens não probabilísticas e, constiste em selecionar participantes que sejam prontamente acessíveis, mesmo com a possibilidade de atingir toda a população ${ }^{10}$.

Foram selecionados dez alunos de cursos de Psicologia sem distinção de gênero ou orientação sexual, sendo os únicos critérios de seleção o fato de serem estudantes de Psicologia acima do sétimo semestre e, que não fossem colegas dos pesquisadores. Os participantes eram de uma cidade do interior paulista, escolhida através de uma amostragem por acessibilidade, ou seja, selecionada de acordo com a disponibilidade para deslocamento e posterior realização da pesquisa.

Para a coleta de dados foi utilizada uma ficha de identificação com dados que não expunham a identidade do sujeito participante e um roteiro para entrevista semiestruturada com 07 (sete) questões que incluiam a análise de situações fictícias abrangendo os temas de Políticas Públicas e atuação do Psicólogo em diversos contextos, dentro do tema central de diversidade sexual.

Após a aprovação do projeto de pesquisa pelo Comitê de Ética, os pesquisadores entraram em contato pessoal com os alunos de Psicologia de acordo com os critérios previstos. Foi informado que seria realizada uma entrevista com sete questões abertas e, solicitada autorização dos mesmos para gravar o áudio de suas respostas para posterior transcrição.

Para organizar e analisar os dados foi utilizada a estratégia de núcleos de significação proposta por Aguiar, Ozella $^{11}$ que, após colher e transcrever os dados, realiza diversas leituras de modo a se familiarizar com os discursos apresentados a fim de apreender as principais temáticas da narrativa e caracterizá-las em pré-indicadores, contribuindo para a construção dos núcleos de significação.

\section{RESULTADOS E DISCUSSÃO}

Os resultados foram obtidos com base em uma amostra de 10 (dez) entrevistas com estudantes de Psicologia, sendo estes 6 (seis) do oitavo semestre, 1 (um) do nono semestre e 3 (três) do décimo semestre. Destes, 9 (nove) declararam que estavam matriculados em instituições privadas de ensino, e 1 (um) declarou que estudava em uma instituição municipal. Dentre os 10 (dez) entrevistados, 3 (três) declararam-se pertencentes ao gênero masculino e 7 (sete) do gênero feminino. A média de idade dos participantes foi de 22 anos, sendo a menor idade 20 anos e a maior idade 26 anos.

Todos os participantes mencionaram que o tema Diversidade Sexual é discutido no curso, sendo que a variação encontrada foi referente à forma como tais questões são abordadas. As opções disponíveis eram através do "conteúdo de uma disciplina", de "eventos (palestras, roda de conversa e outros)", ou ainda, a opção "outros", devendo nesta especificar qual era a forma utilizada para a discussão do conteúdo. Destaca-se que os estudantes poderiam marcar uma, todas ou nenhuma das opções disponíveis.

Desse modo, 4 (quatro) participantes afirmaram que a temática é abordada através de conteúdo de uma disciplina e por eventos de forma conjunta. De forma isolada, a opção "conteúdos de uma disciplina" foi selecionada por 3 (três) pessoas entrevistadas, e "eventos" somente por (1) uma delas. A opção "outros" foi selecionada por apenas 1 (um) dos participantes, mencionando que a temática é apresentada através de discussões, enquanto que, somente 1 (um) dos estudantes mencionou que o conteúdo é abordado de todas as formas.

Destaca-se que houve divergências de informações, visto que alunos da mesma turma e mesma instituição 
selecionaram opções diferentes frente à forma como a temática é abordada.

Com exceção de três participantes, todos mencionaram que o tema é discutido de forma insuficiente, demonstrando interesse na temática e compreensão acerca de sua relevância social. Tal discurso pode ser verificado no seguinte trecho:

“(...) Considero importantes, (discussões sobre o tema) mas nem sempre suficientes, pois faltam mais discussões sobre o tema, pois ainda existem muita discriminação e rejeição por parte das pessoas".

Os participantes que mencionaram que o assunto é suficientemente explanado relataram não possuir interesse na temática ou não souberam opinar acerca do motivo de tal reflexão, como citado no seguinte trecho:

“(...) Considero tais discussões suficientes, pois não me interesso pelo assunto, não é prioritário".

É importante mencionar que a primeira entrevista e a última ocorreram com bastante diferença em relação às datas de agendamento. Tal fato é atribuído à dificuldade para encontrar estudantes dispostos a participar da pesquisa, dado que houve casos de desistência após o pesquisador informar a temática a ser pesquisada ou que o áudio da entrevista seria gravado. Em tais casos, pode-se levantar a hipótese de que os participantes estariam com receio de avaliação e julgamentos, ou exposição de preconceitos. Em relação às questões da entrevista, destaca-se que todas foram respondidas por todos os participantes sem quaisquer problemas.

A análise dos resultados permitiu identificar a prevalência de discursos constituídos de uma pré-concepção sobre o tema, podendo inferir a determinado preconceito de forma velada. Pôde-se encontrar ainda desconhecimento por parte de alguns participantes no que se refere à diferença dos termos "opção" e orientação sexual, conforme trecho abaixo:

“(...) é uma condição dela, é uma opção sexual que ela tem na vida dela e que não deve ser vista como uma coisa totalmente contrária (...) a mãe precisa entender também essa opção da filha, por não ser uma coisa que ela está acostumada desde pequena".

Situação 1 - abordava sobre a atuação do psicólogo frente ao conflito familiar sobre cirurgia de redesignação sexual, e teve como núcleo a "autonomia do paciente $e$ esclarecimento sobre procedimento cirúrgico à família do mesmo", sendo o enunciado presente em todas as entrevistas, ressaltando-se que a compreensão que os estudantes possuem sobre a atuação do Psicólogo frente ao conflito familiar e objeção desta no procedimento de redesignação sexual, de que tal profissional deve posicionar-se de acordo com o estabelecido pela ética e preservação da autonomia do atendido, bem como esclarecer ao familiar de modo a contribuir na eliminação do preconceito deste. Tal discurso pode ser verificado no seguinte trecho:

“(...) Ao meu ver seria uma postura de integrar o pai nesse processo do filho, ou seja, trazê-lo para dentro do procedimento é orientando ele de como acontece o processo que é feito, até tentar fazer é intervenções familiares para deixar o pai esclarecido e tranquilizado diante do... Do procedimento, mas eu penso que a opinião diante dessa situação ela é importante que ela seja inserida no processo, porém não altera a decisão final tomada pelo filho ou filha sobre a cirurgia, né a psicóloga vai fazer essa intervenção familiar de orientação esclarecimento de aumento melhoria de vínculo, porém não retira o laudo de favorável ao procedimento".
Na questão (B), observou-se adequado discernimento no que se refere a atuação do Psicólogo com equipe multiprofissional, obtendo como indicador o "estabelecimento quanto à importância ao acompanhamento pós-cirúrgico e, orientação ao paciente e ao seu familiar quanto às mudanças decorrentes do processo", o que pode ser verificado no trecho abaixo:

“(...) um tipo de cirurgia dessa acaba envolvendo não só uma mudança biológica no ser humano, mas também uma mudança na parte psicológica dele também, no envolvimento que ele tem na sociedade né, com todos os seus familiares, seus amigos, né, emprego, estudos, enfim, então acredito que a importância dessa equipe multidisciplinar numa cirurgia dessa se dá justamente por todas as necessidades do indivíduo, não só na parte biológica".

Situação 2 - discorria o tema central de adoção homoafetiva e pôde-se levantar como núcleo "ir contra a postura da assistente social", tendo em vista que a maioria dos entrevistados compartilhou de tal pensamento, porém houve divergências, pois alguns entrevistados demonstraram a importância de uma avaliação integral no processo de adoção, mostrando a relevância de uma equipe multidisciplinar durante o procedimento. Houve uma entrevistada que apresentou conhecimento dicotômico em relação ao processo, podendo-se compreender que seus sentidos frente ao significado da atuação profissional do Psicólogo pautam-se apenas em se apropriar do conhecimento do âmbito psicológico.

Ressalta-se discurso apresentado por um dos universitários entrevistados sobre o tema de adoção homoafetiva, que esta influencia na orientação sexual da criança adotada, demonstrando um pré-conceito sobre as famílias compostas por casais do mesmo sexo, conforme exposto no trecho abaixo:

“(...) duas mulheres que adotam uma criança, dois homens que adotam uma criança, então eles vão acabar assim, de certa forma, incentivando também a criança; se a criança for menina vai incentivar ficar com outras meninas, se for menino vai incentivar ficar com outros meninos, e não que seja errado, mas acaba influenciando a criança".

Situação 3 - o tema central era de orientação sexual e levantou-se como núcleo "esclarecer aos pais sobre a importância de um processo de orientação e prevenção", visto que a maioria dos estudantes entrevistados citou tal postura diante do caso apresentado. Portanto, pode-se observar uma perspectiva crítica e reflexiva dos entrevistados sobre o tema, visando à importância de um trabalho de orientação e prevenção acerca da orientação sexual, o que pode ser verificado no seguinte trecho:

“(...) Eu acho que a prevenção, a palavra prevenção já diz tudo, não importa a idade, a prevenção tem que ser feita, e se nesse bairro tem essa alta incidência, ela tem que vir mesmo, com esse trabalho, pra prevenir.."

Situação 4 - o tema central era a atuação do Psicólogo frente às Políticas Públicas para a População LGBTT's, pôde-se levantar como núcleo o "Enfrentamento do preconceito, fortalecimento e esclarecimento de direitos", visto que é a temática apresentada com maior frequência nas respostas, sendo esta, portanto, a compreensão que a maioria dos estudantes obtém acerca do papel do Psicólogo frente a tais questões. Também foi citada a contribuição que a Psicologia, enquanto ciência, pode dar na elaboração dessas políticas. Tal discurso pode ser verificado no seguinte trecho: 
“(...) a gente trabalha em prol da atenção pra uma minoria, ou várias minorias que são excluídas ou que não tenham seus direitos, né, merecidos, já vigentes, pra que essas políticas sejam criadas, então... meio que andam lado a lado, né, a Psicologia e a criação de novas políticas que abranjam a maior parte da sociedade e não só uma pequena parcela".

Situação 5 - abordava a compreensão que os acadêmicos possuíam acerca da importância do investimento orçamentário nas Políticas Públicas para a População LGBTT's. Nesta, pode-se levantar como núcleo "Importância das Políticas Públicas", visto que foi a temática mais abordada dentre os participantes, no qual a maioria considera que tal investimento é de grande importância devido ao intenso preconceito ainda intrínseco a sociedade, de modo que tais políticas possam contribuir para a efetivação e garantia dos direitos da População LGBTT's, além de possibilitar a orientação e capacitação de profissionais para combater o preconceito a contribuir com a promoção de igualdade.

Com exceções, dois estudantes discordaram da importância do investimento orçamentário mencionando que este deve ser realizado para a população em geral, sem especificações, ou ainda que a educação é prioridade para combater o preconceito, demonstrando certo desconhecimento acerca da situação enfrentada por tal minoria no país, ou ainda, em relação ao próprio conceito de Política Pública. Tal discurso pode ser verificado no seguinte trecho:

“(...) eu acho que seria muito mais... Ah muito mais gratificante você investir na área da educação pra que esse, esses tipos de violência, esses exemplos de violência que vem acontecendo, não seja tão frequentes, do que investir exatamente na população LGBT",

Situação 6 - abordou a postura do Psicólogo frente a uma solicitação de "mudança de comportamento homossexual", popularmente conhecida como "cura gay", por parte de uma mãe para com sua filha homossexual, e obteve como respostas dentre todos os discursos dos participantes, por unanimidade, a rejeição da proposta, auxiliada a uma ênfase na necessidade de se orientar a mãe para que esta compreenda e aceite a orientação sexual da filha. Alguns participantes chegaram a mencionar a necessidade de se orientar a filha em relação à própria sexualidade, dado que esta é adolescente, para que aprenda também a lidar com as atitudes preconceituosas da mãe, o que pode ser verificado no trecho abaixo:

“(...) Bom, a postura do psicólogo responsável pelo atendimento deste caso, eu penso que seria o que conduzir tanto a mãe como a filha para terapia, e nenhum dos casos para mudar para mudar ou alterar ou "curar" essa situação de homossexualidade".

Desse modo, verificou-se que os estudantes de Psicologia compreendem que a postura do Psicólogo deve ser de orientação, visando romper paradigmas e preconceitos, sem compactuar com a disseminação do preconceito, indo de encontro com princípios abordados nos artigos do Código de Ética Profissional ${ }^{12}$, com ênfase no artigo $2^{\circ}$, que menciona que "ao psicólogo é vedado, praticar ou ser conivente com quaisquer atos que caracterizem negligência, discriminação, exploração, violência, crueldade ou opressão" $" 12$.

Situação 7 - possuía como tema central a temática de gênero e pôde-se levantar como núcleo a "orientação aos pais acerca do conceito de gênero e capacitação dos agentes escolares para lidar com esta temática", visto que, na maioria das entrevistas, foram citados tais posicionamentos por parte dos entrevistados. Portanto, podese inferir que os acadêmicos entrevistados, em sua maioria, possuem uma visão reflexiva acerca da temática de gênero, buscando o esclarecimento aos pais acerca de tal conceito, destacando que a brincadeira não possui influência sobre a orientação sexual da criança, bem como, a importância de capacitar professores e demais agentes escolares para lidar com essa questão na escola.

Destaca-se a entrevistada que mencionou a necessidade de orientar os pais no sentido de aceitar a orientação sexual da criança, pois afirmou que o garoto, por brincar com bonecas, maquiagem e cabelo, seria homossexual. Tal discurso pode ser confirmado através do trecho:

“(...) eu acredito que quando a pessoa é pra ser homossexual, ela nasce homossexual; eu não acredito que seja frescura, seja doença, ou que seja um demônio, ou que é... como que fala? Sem 'vergonhisse'... eu não vejo dessa forma (...). Nessa situação eu acho que eu conversaria não com a criança, mas com os pais, né, nesse sentido de aceitação, né. Porque é uma criança que tem os trejeitos, que gosta de determinada coisa fora do padrão (...) eu acho que teria que conversar nesse sentido da aceitação... você vai deixar de amar seu filho porque ele é homossexual? Não".

Diante da análise dos resultados obtidos, verificou-se ocorrência da confirmação da hipótese inicial em alguns casos. Contudo, destaca-se que tais casos configuram uma minoria na totalidade da pesquisa. Em sua prevalência, os acadêmicos apontaram ao longo de suas respostas enquanto futuros profissionais da Psicologia, posturas que salientam a importância de uma atuação reflexiva, pautada na ética, visando à orientação e informação acerca dos temas que envolvem a diversidade sexual, buscando superar visões equivocadas, esclarecer e desmistificar pré-conceitos, promovendo a inclusão daqueles que sofrem discriminação.

No que concerne à importância das Políticas Públicas à População LGBTT's, é pertinente ressaltar que os acadêmicos entrevistados consideram, em sua maioria, investimentos em tais Políticas essenciais, devido ao preconceito ainda presente em nossa sociedade, de modo que tais Políticas possam contribuir para a efetivação e garantia dos direitos da População LGBTT's.

Para afirmar os sentidos pessoais internalizados, destacam-se os discursos em que os entrevistados utilizaram o termo "opção" sexual, a qual infere que o indivíduo possui escolha quanto à sua orientação e assuntos relacionados a própria sexualidade. A orientação afetivo-sexual caracterizada pela manifestação de desejos por pessoas do mesmo sexo biológico não se reduz a simples escolha ou opção. Ademais, determinado relato mencionou que o sujeito "nasce homossexual", excluindo a construção histórica e social existente, conforme pressuposto da perspectiva histórico cultural. Um dos estudantes mencionou em seus discursos a homossexualidade como comportamento, compreendendo tal orientação como algo simplesmente transitório.

Em relação à adoção homoafetiva, perceberam-se discursos de pré-conceito, onde se afirmou que a criança adotada por casal homoafetivo recebe influência dos mesmos para tornar-se homossexual. Tal concepção extingue a compatibilidade do desenvolvimento psicossocial da criança educada por casais heteroafetivos.

$$
\text { (...) pesquisas realizadas nos }
$$
corroboram com a ideia de que as 
crianças criadas por casais homoafetivos não têm seu desenvolvimento prejudicado e que estão sujeitas a problemas como qualquer outra criança criada por outras pessoas, sendo que a orientação sexual dos pais independe do papel exercido por eles. $\mathrm{O}$ fato de possuir duas mães ou dois pais não representa uma tendência a homoafetividade para a criança, pois se fosse assim, os filhos de pais e mães solteiras teriam sua orientação sexual direcionada a homoafetividade, em virtude da ausência de uma das figuras. Não existe, dessa forma, um determinismo psíquico, pois cada ser humano é único $^{13}$.

Contudo, podemos salientar na análise dos discursos a partir da perspectiva da Psicologia Histórico-Cultural, que os significados sociais dos estudantes de psicologia pesquisados, acerca da diversidade sexual e do fazer psicológico são produções históricas e compartilhadas, as quais são internalizadas e transformadas em sentidos. No que se refere ao sentido, este não se trata apenas de mera reprodução do que já fora produzido, mas sua constituição tece com base na dialética interna/subjetiva ${ }^{14}$.

O conceito de sentido de acordo com essa perspectiva remete a uma compreensão singular do sujeito. À vista disso, os significados são produções históricas e sociais que adquirem no âmbito do ser humano, um sentido pessoal relacionado com a realidade e a própria vida. São, portanto, sentidos compartilhados onde cada sujeito atribui sentidos à realidade da qual se apropria ${ }^{14}$.

\section{CONCLUSÃO}

A pesquisa realizada foi extremamente importante e alcançou com êxito o objetivo ao qual se propôs, possibilitando compreender, dentro dos parâmetros da amostra utilizada, os sentidos e significados de estudantes de Psicologia sobre diversidade sexual e a respeito da prática profissional do Psicólogo em contextos das Políticas Públicas, no enfrentamento dos processos de exclusãoinclusão das diferentes formas de manifestação da sexualidade humana.

A análise, sobre a atribuição de sentidos e significados dos estudantes de psicologia pesquisados, com base na Psicologia histórico-cultural permitiu identificar discursos em que foi observado desconhecimento por parte de alguns estudantes sobre temas específicos da diversidade sexual, os quais foram atribuídos sentidos preconceituosos internalizados de acordo com os significados sociais, onde tal concepção sucedeu-se de forma velada.

Conclui-se que há a necessidade de possíveis revisões das grades curriculares nos cursos de Psicologia, uma vez que é previsto nas Diretrizes Curriculares Nacionais para esta graduação, em seu art. $3^{\circ}$, inc. V, que a mesma deve assegurar uma formação que possibilite ao graduando uma "atuação em diferentes contextos, considerando as necessidades sociais e os direitos humanos, tendo em vista a promoção da qualidade de vida dos indivíduos, grupos, organizações e comunidades"15.

Ademais, a pesquisa revelou uma visão pertinente dos futuros profissionais da Psicologia, estando de acordo com o Código de Ética Profissional, que em seu $1^{\circ}$ princípio fundamental menciona que “o Psicólogo baseará o seu trabalho no respeito e na promoção da liberdade, da dignidade, da igualdade e da integridade do ser humano, apoiado nos valores que embasam a Declaração Universal dos Direitos Humanos" 12 .

Diante do exposto, considera-se que essa pesquisa suscita possíveis direções para novos estudos ligados ao tema da diversidade sexual, tais como a análise das grades curriculares dos cursos de graduação em Psicologia e sua adequação as Diretrizes Curriculares Nacionais, visando compreender se estes têm contemplado de forma satisfatória essa temática. Propõe-se a investigação de forma mais ampla da visão dos estudantes de Psicologia acerca da explicitação e suficiência deste assunto ao longo da graduação, para possíveis sugestões de melhor apropriação deste conteúdo, uma vez que a maior parte dos entrevistados declararam que o tema é abordado de forma insuficiente durante do curso. Destarte, considera-se esta uma questão relevante não só ao âmbito acadêmico, mas fundamentalmente à sociedade.

\section{REFERÊNCIAS}

1. Roselli-Cruz A. Homossexualidade, homofobia e a agressividade do palavrão: seu uso na educação sexual escolar. Educ rev. 2011; 39:73-85.

2. Perucchi J, Brandao BC, Vieira HIS. Aspectos psicossociais da homofobia intrafamiliar e saúde de jovens lésbicas e gays. Estud psicol (Natal). 2014; 19(1): 67-76.

3. Nascimento LCS, Pimentel A. Delegacia e defensoria pública no combate à homofobia em Belém do Pará. Barbaroi. 2011/2; 35:43-57.

4. Santos DK. As produções discursivas sobre a homossexualidade e a construção da homofobia: problematizações necessárias à psicologia. Rev Epos. 2013; 4(1).

5. Borges ZN, Passamani GR, Ohlweiler MI, Bulsing M. Percepção de professoras de ensino médio e fundamental sobre a homofobia na escola em Santa Maria (Rio Grande do Sul/Brasil). Educ rev. 2011; 39:21-38.

6. Junqueira RD. "A homofobia não é um problema. Aqui não há gays nem lésbicas!” Estratégias discursivas e estados de negação da discriminação por orientação sexual e identidade de gênero nas escolas. Rev Psicol UNESP. 2010; 9(1):123-39.

7. Brito W, Maroja D, Mello L. Políticas públicas para a população LGBT no Brasil: notas sobre alcances e possibilidades. Cad Pagu. 2012; 39:403-29.

8. Andriani AGP, Rosa EZ. Psicologia sócio-histórica: uma tentativa de sistematização epistemológica e metodológica. In: Kahhale E. M. P. (org.) A diversidade da psicologia: uma construção teórica. São Paulo: Cortez; 2002.

9. Marques LP, Marques CA. Dialogando com Paulo Freire e Vygotsky sobre Educação. In: Reunião Anual da Associação Nacional de Pós-Graduação e Pesquisa em Educação (ANPED), 29, 2006, Caxambu/MG.

10. Oliveira KD, Almeida KL, Barbosa TL. Amostragens probabilística e não probabilística: técnicas e aplicações na determinação de amostras. Jerônimo Monteiro: Universidade Federal do Espirito Santo; 2012.

11. Aguiar WMJ, Ozella S. Núcleos de significação como instrumento para a apreensão da constituição dos sentidos. Psicol cienc prof. 2006; 26(2):222-45.

12. Conselho Federal de Psicologia. Resolução CFP N. 010/2005. Código de ética profissional do psicólogo. Brasília, CFP, 2005. 
13. Ferreira KCG, Chalhub A. Contribuições da psicologia em relação à adoção de crianças por casais homoafetivos: uma revisão de literatura. Rev (Inter)Subjetividades. 2010; 2(1):29-49.

14. Schweitzer L, Gonçalves J, Tolfo SR, Silva N. Bases epistemológicas sobre sentido(s) e significado(s) do trabalho em estudos nacionais. Rev Psicol Organ Trab. 2016; 16(1):103-16.

15. Brasil. Ministério da Educação: Resolução $\mathrm{N}^{\circ} 5$, de 15 de março de 2011. Conselho Nacional de Educação Câmara de Educação Superior. Resolução CNE/CES 5/2011. Diário Oficial da União, Brasília, 16 de março de 2011 - Seção 1 - p. 19

\section{CONFLITO DE INTERESSES}

Os autores declaram não haver conflitos de interesse.

\section{AUTOR PARA CORRESPONDÊNCIA}

Flávia Cristina Santiago de Oliveira

flaviasantiago.oliveira@hotmail.com

Submetido em 06/03/2017 Aceito em 22/03/2017 